\title{
Effects of lovastatin on hepatic expression of the low-density lipoprotein receptor in nephrotic rats
}

\author{
L.X. Wei, L. Chen, W.M. Wang, X.H. Zhang, J.B. Wu, S.F. Liang and \\ G.Y. Shu
}

Department of Nephrology, Fujian Provincial Hospital, Fujian Medical University, Fuzhou, China

Corresponding author: L.X. Wei

E-mail: lixinwei66@126.com

Genet. Mol. Res. 13 (1): 938-944 (2014)

Received December 13, 2012

Accepted June 23, 2013

Published February 19, 2014

DOI http://dx.doi.org/10.4238/2014.February.19.4

\begin{abstract}
To investigate the effect of the HMG-CoA reductase inhibitor lovastatin on the expression of the receptor for hepatic lowdensity lipoprotein (LDL) in a rat model with kidney disease, and to identify the mechanisms in statin treatment of nephrotic syndrome with hyperlipidemia, a rat model with nephrotic syndrome was established. Thirty male Sprague-Dawley rats were treated with lovastatin for 2 weeks using gavage. The expression of protein and mRNA of the LDL receptor in the rat liver was detected with Western blot and RT-PCR, respectively, and blood-biochemical indices were also recorded for each group. Compared with the untreated control group, lovastatin treatment significantly decreased the levels of serum total cholesterol, LDL cholesterol, triglycerides, and urinary protein. In addition, lovastatin treatment significantly increased the levels of serum albumin and hepatic LDL receptor proteins, but had no effect on the expression of hepatic LDL receptor mRNA. Treatment with lovastatin markedly increased the expression of the hepatic LDL receptor in rats with nephrotic syndrome, which was accompanied by significantly improved hyperlipidemia.
\end{abstract}

Key words: Nephrotic syndrome; Lovastatin; LDL receptor 


\section{INTRODUCTION}

Hyperlipidemia is one of the main features of the nephrotic syndrome, which is characterized by elevated total and low-density lipoprotein (LDL) cholesterol in serum. Nephrotic syndrome also causes common hypertriglyceridemia and increases the lipoproteins apo-B, apo-C-II, and apo-E. However, levels of apo-A and apo-A-II are usually normal in this syndrome, whereas the level of high-density lipoproteins (HDL) is normal or decreased (Kronenberg, 2005; Mahmud et al., 2011). However, the relationship between nephrotic syndrome and hyperlipidemia remains unclear. Recent studies have focused on the role of hyperlipidemia in increased glomerular sclerosis (Lee, 2011; Gyebi et al., 2012), a malady of increasing concern. Studies have also shown that hyperlipidemia associated with nephrotic syndrome significantly increases the risk of concurrent cardiovascular disease, and that it is one of the reasons for the high incidence of complications arising from atherosclerosis (Lacquaniti et al., 2010; Burst and Benzing, 2011). Hyperlipidemia is also associated with thrombosis (Fervenza et al., 2008). Accordingly, the incidence of venous thromboembolism, a common complication in nephrotic syndrome, is decreased by treatment with statins (Resh et al., 2011) such as 3-hydroxy-3-methyl coenzyme A (HMG-CoA) reductase inhibitors. These statins inhibit HMG-CoA reductase activity, especially in the liver (da Costa et al., 2012), which decreases the cholesterol levels in hepatic cells and stimulates the expression of hepatic LDL receptor mRNA and protein. Serum LDL cholesterol is then absorbed and metabolized in the liver, resulting in decreased serum cholesterol levels (Ma et al., 1986; Bradford et al., 1991). Studies of familial hypercholesterolemia patients who lack the LDL receptor have clearly shown that this receptor is important for decreasing serum cholesterol. The LDL receptor deficiency in these patients means that even large doses of the HMG-CoA reductase inhibitor lovastatin cannot effectively decrease serum cholesterol levels (Uauy et al., 1988).

The usefulness of the application and the mechanisms of action of statins in nephrotic syndrome remain unclear. However, several studies have shown that statins are effective in treatments of hyperlipidemia in nephrotic syndrome (Kasiske, 1998; Pyram et al., 2012). This poses the following question: Are the mechanisms for lowering lipids in nephrotic syndrome the same as those mentioned above?

To address this question, we created a rat model of nephrotic syndrome by administering doxorubicin. We then treated the animals of this model with lovastatin to test its influence on hepatic LDL receptor mRNA and protein expression. This study aimed to partially clarify the mechanism of statin treatment of hyperlipidemia in nephrotic syndrome.

\section{MATERIAL AND METHODS}

\section{Animal models and delivery method}

Thirty male Sprague-Dawley rats weighing 250-300 g (Department of Experimental Animal Center) had free access to water and feeding, were observed for 1 week, and randomly divided into three groups: 10 animals in the normal control group, 10 in the nephrotic syndrome group $(\mathrm{N})$, and 10 in the lovastatin group (L). Production of the $\mathrm{N}$ and $\mathrm{L}$ groups was performed according to nephrotic syndrome model-making methods described by Okuda et al. (1986). On the 1st and 14th days, the animals in groups $\mathrm{N}$ and $\mathrm{L}$ received intravenous injections of $3.5 \mathrm{mg} /$ $\mathrm{kg}$ doxorubicin (Italy Aibo Pharmaceutical Company). The normal control group received saline by tail vein injection twice at the same time as the other two groups. After the 2nd doxorubicin 
injection, the rats were observed for 2 weeks. The 24-h urinary protein was measured in each group at the 4th week: the normal control group had $4.08 \pm 3.51 \mathrm{mg} / 24-\mathrm{h}$ urinary protein and the model group (comprising the nephrotic syndrome and the lovastatin groups) had $183.27 \pm 50.04$ $\mathrm{mg} / 24$-h urinary protein, indicating massive proteinuria in the model groups consistent with the formation of nephrotic syndrome in these animals. From the 5th week, group L received lovastatin (Hi-sun Pharmaceutical Co., Ltd.) dissolved in saline, with a dose of $20 \mathrm{mg} / \mathrm{kg}$ per day by gavage treatment. The nephrotic syndrome and normal control group received gavage treatment with saline only. The treatment period was 2 weeks.

\section{Material drawn}

The 24-h urine of rats in each group was collected after 2 weeks of treatment. After anesthesia with $50 \mathrm{mg}$ sodium pentobarbital/kg body weight by intra-peritoneal injection, the abdominal cavity was opened. The abdominal aortic serum was separated and stored $-20^{\circ} \mathrm{C}$; the liver tissue was immediately removed, transferred to liquid nitrogen, and then stored at $-80^{\circ} \mathrm{C}$.

\section{Detection methods}

The 24-h urinary protein was measured by Coomassie Brilliant Blue G250, and the biochemical analysis of blood was performed with a Hitachi 7060 automatic biochemical analyzer. LDL receptor protein in liver tissues was determined by Western blot. To extract proteins from liver tissue, its volume was measured and 2 volumes of ice-cold cell lysis buffer were added on ice. To homogenize the tissue, the tissue-buffer mixture was subjected to ultrasound for $30 \mathrm{~s}$, transferred to a boiling water bath for $5 \mathrm{~min}$, immediately placed on ice for $2 \mathrm{~min}$, and centrifuged at $12,000 \mathrm{rev} / \mathrm{min}$ and $4^{\circ} \mathrm{C}$ for $5 \mathrm{~min}$. The supernatant was used to determine protein concentrations. Total protein $(30 \mu \mathrm{g})$ from each specimen was loaded onto $10 \%$ SDSPAGE; after electrophoresis, fractionated proteins were transferred to membranes, which were incubated with murine multiple anti-bovine LDL receptor antibody (Chemicon Company) at $37^{\circ} \mathrm{C}$ for $2 \mathrm{~h}$ and then at $4^{\circ} \mathrm{C}$ overnight. The membranes were subjected to 3 washes of $10 \mathrm{~min}$ each with PBS containing $0.05 \%$ Tween 20 . This was followed by incubation with the second antibody [horse radish peroxidase-labeled goat anti-mouse $\operatorname{IgG}(1: 1000)]$ at room temperature for $1 \mathrm{~h}$, and by another 3 washes as described above. The membranes were immersed in LuMino substrate buffer and gently shaken. After exposure, developing, and fixing, protein bands were semi-quantitative analyzed with an image-analysis system.

To extract total RNA, $1 \mathrm{~mL}$ Trizol reagent was added to $100 \mathrm{mg}$ liver tissue, followed by homogenization and extraction by the chloroform method. To remove contaminating DNA, the total RNA was incubated with RNase-free DNase I at $37^{\circ} \mathrm{C}$ for $10 \mathrm{~min}$, followed by DNaseI inactivation at $70^{\circ} \mathrm{C}$ for $15 \mathrm{~min}$. The RNA obtained was reverse transcribed and taken up in 2 $\mu \mathrm{L}$; the cDNA product was then used as template for PCR amplification. The primers for the LDL receptor were the following: upstream primer (5'-TTCCTCGAACAAATACTCCG-3') and downstream primer (5'-TGCCTCAACCACCCAGAC-3'). PCR thermal cycling conditions were the following: 35 cycles of denaturation at $95^{\circ} \mathrm{C}$ for $1 \mathrm{~min}$, annealing at $56^{\circ} \mathrm{C}$ for $1 \mathrm{~min}$, and elongation at $72^{\circ} \mathrm{C}$ for $1.5 \mathrm{~min}$. The length of the amplification product was $419 \mathrm{bp}$. The $\beta$-actin gene (primers of $\beta$-actin were purchased from Clontech) was amplified as an internal control. Gel electrophoresis images were uploaded into a Kodak gel analysis system to calculate absorbance ratios (as a relative measure of expression) to determine expression of the LDL receptor gene relative to that of the $\beta$-actin gene. 


\section{Statistical methods}

The experimental data are reported as means \pm standard deviation. Statistical significance of differences between two groups was assessed by using the $t$-test. A P $<0.05$ was considered to be statistically significant.

\section{RESULTS}

\section{Biochemical indices of blood and results of the urine protein test}

As shown in Table 1, the untreated nephrotic syndrome group showed severe proteinuria and significant hypoalbuminemia; in addition, serum total cholesterol, LDL cholesterol, and triglyceride concentrations were also significantly higher than in the healthy control group. Compared with the nephrotic syndrome group, treatment with lovastatin for 2 weeks significantly decreased serum total cholesterol, LDL cholesterol, and triglyceride concentrations $(\mathrm{P}<0.05)$. Hypoalbuminemia was also significantly improved in the lovastatin group, along with a significant decrease in urinary protein $(\mathrm{P}<0.05)$. Serum creatinine levels did not exhibit any significant differences among the groups $(\mathrm{P}>0.05)$.

Table 1. Results from blood chemistry and urinary protein of rats in each group.
\begin{tabular}{lcccccc}
\hline Groups & $\begin{array}{c}\text { Total cholesterol } \\
(\mathrm{mM})\end{array}$ & $\begin{array}{c}\text { LDL-cholesterol } \\
(\mathrm{mM})\end{array}$ & $\begin{array}{c}\text { Triglyceride } \\
(\mathrm{mM})\end{array}$ & $\begin{array}{c}\text { Albumin } \\
(\mathrm{g} / \mathrm{L})\end{array}$ & $\begin{array}{c}\text { Creatinine } \\
(\mu \mathrm{M})\end{array}$ & $\begin{array}{c}\text { Urinary protein } \\
(\mathrm{mg} / 24 \mathrm{~h})\end{array}$ \\
\hline Control & $1.28 \pm 0.19$ & $0.59 \pm 0.09$ & $0.45 \pm 0.07$ & $35.58 \pm 3.17$ & $49.36 \pm 6.15$ & $5.07 \pm 2.38$ \\
Nephrotic syndrome & $7.28 \pm 1.20^{*}$ & $4.77 \pm 0.78^{*}$ & $2.01 \pm 0.33^{*}$ & $12.06 \pm 1.99^{*}$ & $53.15 \pm 9.73$ & $307.55 \pm 35.89^{*}$ \\
Lovastatin & $2.26 \pm 0.96^{* \Delta}$ & $0.89 \pm 0.38^{* \Delta}$ & $0.93 \pm 0.39^{* \Delta}$ & $20.16 \pm 4.38^{* \Delta}$ & $50.76 \pm 3.15$ & $148.78 \pm 33.42^{* \Delta}$ \\
\hline
\end{tabular}

$* \mathrm{P}<0.05$, compared with the control group. ${ }^{\Delta} \mathrm{P}<0.05$, compared with the nephrotic syndrome group.

\section{Results of the hepatic LDL receptor test}

Hepatic LDL receptor expression was significantly lower in group $\mathrm{N}(\mathrm{P}<0.01)$, which displayed significant improvement after the lovastatin treatment. Although levels of LDL receptor protein in liver tissues were decreased in group $\mathrm{N}$ relative to levels of LDL receptor protein measured in the other two groups, levels of LDL receptor mRNA remained unchanged. Lovastatin treatment did not significantly change the mRNA expression of LDL receptor in liver tissue (Figures 1 and 2).
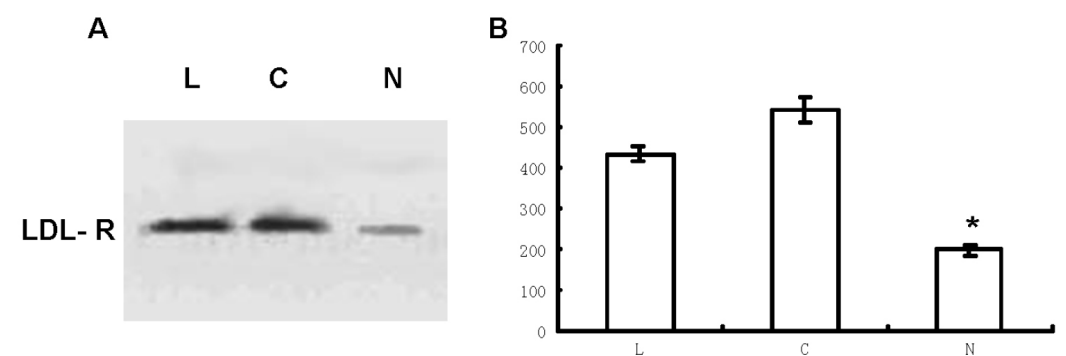

Figure 1. Expressions of LDL receptor (LDL-R) protein in livers of rats in each group. A. Western blot determination of LDL-R in livers of rats in each group. B. Diagram of Western blot analysis. ${ }^{*} \mathrm{P}<0.01$, compared with the other group. $\mathrm{L}=$ lovastatin group; $\mathrm{C}=$ control group; $\mathrm{N}=$ nephrotic syndrome group. 
A

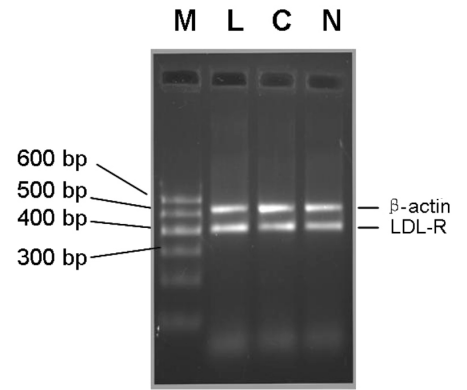

B

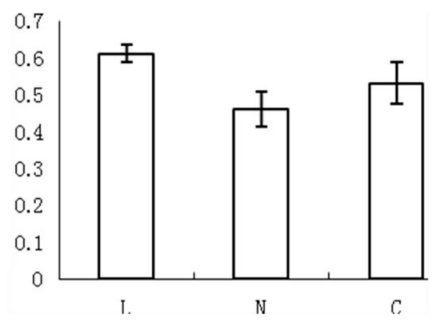

Figure 2. mRNA expressions of LDL receptor (LDL-R) in livers of rats in each group. $\mathrm{M}=$ marker; $\mathrm{L}=$ lovastatin group; $\mathrm{C}=$ control group; $\mathrm{N}=$ nephrotic syndrome group.

\section{DISCUSSION}

In normal physiological conditions, the hepatic cell-surface LDL receptor plays a very important role in the regulation of serum cholesterol. LDL receptor mRNA expression and protein synthesis are mainly affected by the concentration of free cholesterol in the hepatic cells: an increase in intracellular free cholesterol inhibits both expression of LDL receptor mRNA and protein. After synthesis, the LDL receptor expresses on the surface of the hepatic cells; these cells then bind to cholesterol-rich LDL particles in the blood perfusing the liver, and the receptor-bound LDL particles enter hepatic cellular metabolism through LDL receptormediated endocytosis. Once in the hepatic cells, the LDL receptor dissociates from LDL and returns to the cell membrane completing one cycle, and the LDL is degraded in the lysosome, resulting in the release of cholesterol. Only small amounts of the LDL receptor protein are degraded in the cell in every cycle.

The mechanism of hypercholesterolemia in nephrotic syndrome is unclear. Previous studies suggest that hypercholesterolemia in nephrotic syndrome is the result of the following events and mechanisms: 1) Activity of hepatic HMG-CoA, the rate-limiting enzyme in cholesterol biosynthesis, is increased (Vaziri and Liang, 1995; Vaziri et al., 2003); 2) levels of the LDL receptor, the main route of eliminating cholesterol-rich LDL particles, are decreased (Vaziri and Liang, 1996); 3) expression of acyl-CoA cholesteryl ester acyl transferase (ACAT), an enzyme of the endoplasmic reticulum that transfers the acyl-CoA acyl to 3 locations of free cholesterol and leads to cholesterol esterification and cholesterol storage in the cytosol, is upregulated (Vaziri and Liang, 2002); 4) expression of lecithin cholesterol acyl transferase (LCAT), which transfers fatty acids from lecithin on HDL to free cholesterol and contributes to the transfer of esterified cholesterol from the HDL core to the HDL surface during HDL maturation and reverse cholesterol transport (Vaziri et al., 2001), is decreased; 5) a compensatory increase in the activity of hepatic cholesterol 7a-hydroxylase, the rate-limiting enzyme for the conversion of cholesterol to bile acids, is only limited (Liang et al., 1996); and 6) liver apolipoprotein B100 (Apo-B100), which is the major apolipoprotein of LDL and a very LDL (VLDL), is upregulated (Kaysen, 1991). Therefore, as mentioned above, the LDL receptor plays an important role in the formation of hypercholesterolemia in nephrotic syndrome.

A study by Vaziri and Liang (1996) of nephrotic syndrome induced by puromycin showed that levels of the hepatic LDL receptor protein decreased significantly in rats. This 
decrease in LDL receptor protein coincided with increased serum total cholesterol and LDL cholesterol. However, expression of the mRNA for the hepatic LDL receptor was unchanged. The results of our study have shown that the LDL receptor protein decreased significantly in lovastatin-untreated nephrotic syndrome rats compared with the normal control group, and, similar to the observations by Vaziri and Liang (1996), mRNA levels of the LDL receptor gene did not show any significant differences between the two groups. Our study also showed that 2 weeks after lovastatin treatment, the hepatic LDL receptor protein significantly increased in rats with nephrotic syndrome. At the same time, levels of serum total cholesterol, LDL cholesterol, and triglycerides decreased. But the hepatic LDL receptor mRNA did not show significant difference between the lovastatin-treated group and the other two groups. Therefore, we believe that the increase of hepatic LDL receptor protein in the lovastatin-treated nephrotic syndrome rats could be due to lovastatin-induced inhibition of cholesterol biosynthesis in the liver cells. This lovastatin-induced decrease of cholesterol further stimulates LDL receptor protein synthesis. However, expression of hepatic LDL receptor mRNA did not exhibit significant differences in any group, even in the groups in which changes in the levels of hepatic LDL receptor protein were detected. Thus, in rats with nephrotic syndrome that are untreated or treated with lovastatin, levels of the LDL receptor protein appear to be regulated at the level of protein synthesis/ degradation and not at the level of transcription. However, because of the complexity of the metabolism and regulation of the LDL receptor in liver cells, the specific mechanism needs to be further determined. In addition, the significant reduction of proteinuria in the rats with nephrotic syndrome appeared to be associated with the improvement of the LDL receptor.

\section{REFERENCES}

Bradford RH, Shear CL, Chremos AN, Dujovne C, et al. (1991). Expanded Clinical Evaluation of Lovastatin (EXCEL) study results. I. Efficacy in modifying plasma lipoproteins and adverse event profile in 8245 patients with moderate hypercholesterolemia. Arch. Intern. Med. 151: 43-49.

Burst V and Benzing T (2011). Dyslipidemia treatment and cardiovascular disease in the renal patient. Curr. Pharm. Des. 17: 894-907.

da Costa RF, Freire VN, Bezerra EM, Cavada BS, et al. (2012). Explaining statin inhibition effectiveness of HMG-CoA reductase by quantum biochemistry computations. Phys. Chem. Chem. Phys. 14: 1389-1398.

Fervenza FC, Sethi S and Specks U (2008). Idiopathic membranous nephropathy: diagnosis and treatment. Clin. J. Am. Soc. Nephrol. 3: 905-919.

Gyebi L, Soltani Z and Reisin E (2012). Lipid nephrotoxicity: new concept for an old disease. Curr. Hypertens. Rep. 14: 177-181.

Kasiske BL (1998). Hyperlipidemia in patients with chronic renal disease. Am. J. Kidney Dis. 32: S142-S156.

Kaysen GA (1991). Hyperlipidemia of the nephrotic syndrome. Kidney Int. (Suppl 31): S8-S15.

Kronenberg F (2005). Dyslipidemia and nephrotic syndrome: recent advances. J. Ren. Nutr. 15: 195-203.

Lacquaniti A, Bolignano D, Donato V, Bono C, et al. (2010). Alterations of lipid metabolism in chronic nephropathies: mechanisms, diagnosis and treatment. Kidney Blood Press Res. 33: 100-110.

Lee HS (2011). Mechanisms and consequences of hypertriglyceridemia and cellular lipid accumulation in chronic kidney disease and metabolic syndrome. Histol. Histopathol. 26: 1599-1610.

Liang KH, Oveisi F and Vaziri ND (1996). Gene expression of hepatic cholesterol 7 alpha-hydroxylase in the course of puromycin-induced nephrosis. Kidney Int. 49: 855-860.

Ma PT, Gil G, Sudhof TC, Bilheimer DW, et al. (1986). Mevinolin, an inhibitor of cholesterol synthesis, induces mRNA for low density lipoprotein receptor in livers of hamsters and rabbits. Proc. Natl. Acad. Sci. U. S. A. 83: 8370-8374.

Mahmud S, Jahan S and Hossain MM (2011). Hyperlipidemia in childhood idiopathic nephrotic syndrome during initial remission and relapse. Mymensingh. Med. J. 20: 402-406.

Okuda S, Oh Y, Tsuruda H, Onoyama K, et al. (1986). Adriamycin-induced nephropathy as a model of chronic progressive glomerular disease. Kidney Int. 29: 502-510. 
Pyram R, Kansara A, Banerji MA and Loney-Hutchinson L (2012). Chronic kidney disease and diabetes. Maturitas 71 : 94-103.

Resh M, Mahmoodi BK, Navis GJ, Veeger NJ, et al. (2011). Statin use in patients with nephrotic syndrome is associated with a lower risk of venous thromboembolism. Thromb. Res. 127: 395-399.

Uauy R, Vega GL, Grundy SM and Bilheimer DM (1988). Lovastatin therapy in receptor-negative homozygous familial hypercholesterolemia: lack of effect on low-density lipoprotein concentrations or turnover. J. Pediatr. 113: 387-392.

Vaziri ND and Liang KH (1995). Hepatic HMG-CoA reductase gene expression during the course of puromycin-induced nephrosis. Kidney Int. 48: 1979-1985.

Vaziri ND and Liang KH (1996). Down-regulation of hepatic LDL receptor expression in experimental nephrosis. Kidney Int. 50: 887-893.

Vaziri ND and Liang K (2002). Up-regulation of acyl-coenzyme A: cholesterol acyltransferase (ACAT) in nephrotic syndrome. Kidney Int. 61: 1769-1775.

Vaziri ND, Liang K and Parks JS (2001). Acquired lecithin-cholesterol acyltransferase deficiency in nephrotic syndrome. Am. J. Physiol. Renal Physiol. 280: F823-F828.

Vaziri ND, Sato T and Liang K (2003). Molecular mechanisms of altered cholesterol metabolism in rats with spontaneous focal glomerulosclerosis. Kidney Int. 63: 1756-1763. 